\title{
对话周琪: 华盛顿共识
}

基因编辑技术的飞速发展，特别是近年来CRISPR技术的广泛应用，使得人类拥有了前所未有的改变和修饰基因组 的能力. CRISPR技术来源于细菌本身对抗筮菌体的“免疫系统”。这项技术利用单链引导RNA(sgRNA)和Cas9蛋白，可以 在体内和体外简单、迅速、低成本实现基因编辑. 2012年以来, CRISPR技术已经广泛地被全球应用于各个实验室，进行几 乎所有细胞系和大多数常用实验动物的遗传物质改造. CRISPR技术及其应用成果从其发现以来连年入选Nature和Science 杂志评选的年度十大科学发现. 在新出炉的Science 2015 年度十大科学发现中, CRISPR技术位于榜首. CRISPR技术在人 类遗传性疾病、病毒感染疾病和癌症的相关研究中所显示出的效果, 使得人们看到了这项技术的广阔前景和巨大发展潜 力. 但同时, 将基因编辑技术应用于人类本身, 需要考虑的安全性问题和可能引发的一系列社会、伦理问题, 也引起了全 球专家学者和社会大众的广泛关注和讨论.

应此所需, 人类基因编辑国际峰会于 2015 年12月1 3日在美国华盛顿召开. 本次分会由中国科学院、美国科学院、美 国医学科学院和英国皇家学会共同组织举办. 就华盛顿会议相关话题, 我们与本次人类基因编辑国际峰会组委会成员之 一周琪院士进行了对话. 周琪是中国科学院动物研究所副所长, 干细胞与生殖生物学国家重点实验室主任, 是细胞重编 程机制和命运调控、干细胞多能性获得与维持以及人类疾病动物模型方面的专家. 在与周琪的对话中, 他谈到了本次峰 会讨论的内容, 共识的解读以及对基因编辑未来发展的期待.

人类基因编辑国际峰会在分享基因编辑技术进展的同 时, 特别针对人类基因组编辑的社会影响和伦理方面进行 了激烈的讨论. 周琪谈到: “到目前为止, 国际上已经有几 个成功的案例将人类基因编辑技术成功应用于临床, 让大 家看到了该项技术美好的应用前景，但是技术本身的不确 定性、效率和安全性的问题以及伦理方面的问题仍然困扰 着基因编辑技术的发展. 正如此次峰会中大家最为关心的 问题: 如果应用人类基因编辑技术永久性地改变人的遗传 物质中的基因序列, 对后代将产生多大的影响. 这是所有 人都很担心的一个问题”.

“从这次会议的主题角度来看, 大家还是希望能够对这 个技术有一个客观的评价. 所以在这次会议上, 请到了在 基因编辑领域从技术到应用已经做出了突出贡献的科学家 做报告, 充分研讨了技术的发展趋势. 同时, 也有一部分报 告主要讨论生物安全问题, 还有报告讨论到包括伦理、法 律、国家的政策、条例的制定等. 讨论非常热烈和充分”.

在人类基因编辑的未来发展方面, 与会的专家们分别 表达了自己不同的观点: 有些人觉得应该走得更快一些, 有些人觉得应该更谨慎一些. 周琪告诉我们: “在此次会议 上关于人类基因编辑技术的发展和应用存在各种不同的 声音, 包括有与会者提出: 对生殖相关细胞系 (germline)进 行基因编辑没什么不对的, 实际上在开会之前大家对于这 种观点的存在并没有太多的预期”. 这些不同观点的碰撞 引发了热烈的讨论, 在网络上, 大家可以看到 19 小时的 会议相关讨论视频(http://www. nationalacademies.org/geneediting/Gene-Edit Summit/webcast/index.htm). 但周琪表示: “这只是所有讨论里很少的一部分”. 事实上, 会议内容也 同时引起了全世界基因编辑方面专家和社会各界的广泛关

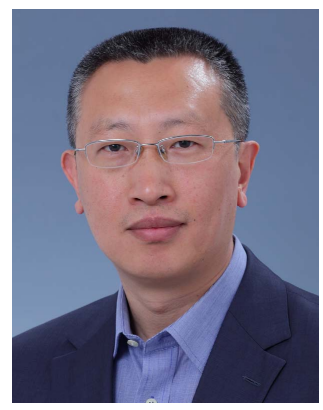

周蜞
注和讨论. 大会的组委会在会议结 束后仍然组织了多次的线上讨论 和电话会议, 鼓励大家发表不同的 看法. 周琪说: “我们开了一次电话 会议, 统计了通过网络参加会议人 员的情况, 从数据看欧美这些国家 参与的人数非常多, 说明这些国家 社会公众对这些问题非常关注”.

会议的最后, 与会科学家们 达成并发布了关于人类基因编辑 的共识, 在共识中写到: 鼓励基因编辑“基础和临床前研 究”及其“在体细胞层面上的临床应用”. 同时, 因为“生殖 细胞的临床应用”将会“作用在被编辑后代的所有细胞上, 该编辑基因会传至其后代并成为人类基因库中的一员”; 大会共识认为, 生殖细胞的基因编辑还存在各种技术层 面、社会层面以及伦理道德层面的问题, 其安全性目前还 无法估计, 且一旦被编辑的基因进人人类基因库，该影响 “不可逆，不受地域限制”. 声明认为“目前为止还不具备进 行任何生殖细胞临床应用的条件”. 此外, 共识还呼吁全 球的关注和持续的国际性讨论.

周琪帮我们解读了这份共识: “虽然有这么多不同的观 点, 最后在声明里大家的基本观点还是一致的, 既鼓励这项 技术不断的发展，也正视这项技术带来的所有的正面的效益 和负面的影响. 同时这次会议上大家也达成了一致, 尤其是 中、美、英 3 个发起国家中的 4 个科研机构联合建议: 在目前 状况下禁止用于人类生殖的相关细胞系(germline)的基因修 饰和编辑, 这也是第一次在这样的国际会议上达成这方面的 共识.”共识为当下的人类基因编辑划了一条“红线”, 即“目 
前状况”下用于“人类生殖”相关基因编辑是“禁止”的. 而谈 到体细胞基因编辑, 周琪表示: “体细胞的基因编辑方面大家 还是有共识的, 因为它的影响是有限的, 因此对于基因编辑 技术在体细胞内的临床应用大家还是一致认可的”.

共识中, 对将应用于生殖的肧胎细胞的基因编辑是禁 止的, 那对不用于生殖的相关细胞的基础研究方面呢? 2015年4月份, 我国科学家黄军就在Protein \& Cell杂志发表 了在人类废弃胚胎细胞中所做的CRISPR/Cas9基因编辑相 关研究, 引发了国内国际广泛关注. 黄军就副教授也因此 研究获评Nature 杂志 2015 年度十大人物. 在与周琪的交流 中, 我们也谈到了这个问题, 这个层面的研究, 在这个共识 里是支持的还是反对的呢? 周琪告诉我们: “这部分工作还 是属于研究范畴. 实际在峰会最后的联合声明公布以后, 有一个很长的记者招待会, 在招待会上有记者问到这个问 题: “这个国际公约和声明对于中国已经开展的相关技术有 没有约束力'. 这个问题是大会主席巴尔的摩主动站出来回 答: “首先中国的这项工作是符合中国的法律, 符合中国的 管理条例, 也是符合中国的伦理管理条例的, 换一句话讲, 这项工作在中国和国际上看来, 都是正当合理合法的. 所以 类似的工作在声明里是不受禁止的, 因为那项工作遵守了 2003年颁布的《人胚胎干细胞研究伦理指导原则》, 按其中 相关规定, 使用的胚胎细胞没有超过 14 天, 并且是一些废弃 的肧胎, 也没有用于移植. 在公约里实际也讲到了, 这些不 以怀孕为目的的基础研究工作是受支持的”.

对未来人类基因编辑的发展方向和“底线”, 基因编辑峰 会所代表的该领域顶尖科学家们达成了一个共识. 会后, 4家 举办单位的院长还发布了联合声明, 称“我们将与全球的学 术界, 与世界范围内的科研和医学机构共同举办持续性的论 坛, 讨论关于人类基因组编辑应用在科研、医学和道德方面 的各种问题. 峰会将调动全球所有可能的专家力量, 帮助整 个社会建立相应于人类基因编辑技术的规则. 这是人类历史 上的重要时刻, 我们有责任为社会各界提供一份基本原则. 这项基本原则将在未来做这项技术发展相关决定的时候, 特 别是在与做后代相关的应用方面的决定的时候发挥作用”.

但是正如周琪讲的, “这种国际共识, 或者叫作国际联 合声明, 它并不具有法律效应, 因此对于此项技术的监管 工作最核心的问题是, 有了这个国际的共识之后各个国 家, 尤其这3个发起国, 应该遵照这些国际的共识, 尽快制 定各自国家的管理条例, 法律法规. 只有到了国家层面制
定的规则才会有法律效应”. 就我们国家的相关政策来说, 他认为: “我们国家随后肯定会有相应跟进的措施. 目前我 们国家已经开始研讨相关政策的制定. 至于推动的速度有 多快, 我们还是很期待的. 国家领导人对人类基因编辑技 术是非常重视的, 有多次明确的指示. 有关的部门也都已 经在调研. 我想我们国家会很快有跟进的相关举措”.

在讨论过一系列人类基因编辑的限制和伦理问题之 后, 谈到未来基因编辑的研究, 周院士回归到基因编辑技 术本身, 以其专业敏锐的眼光一针见血地指出了我们国家 目前在这个领域中存在的问题: “基因编辑技术应用的领域 非常广泛, 而不仅仅用来编辑人类细胞. 从中国来说, 与 美国乃至国际上比, 我们在基因编辑技术本身上所投人的 人力和财力都是不够的. 在这次会议的预备会和几次电话 会议中, 我都讲到, 希望国家能够鼓励、支持、引导科研人 员关注到技术本身，因为这个领域具有巨大的潜力和商机. 如果我们没有在核心的关键技术上有所突破，一味地把国 外开发的成熟技术拿来应用的话, 我们实际等于整个丢掉 了这个领域. 国内现在的研究, 主要还是集中于将国外研 究的技术拿到我们的研究中来应用. 虽然也产生了一批在 国际上很有影响力的论文, 但是在实际成果和将来可能产 生的效益上还有空缺. 作为一个中国科学家, 我期待国家 通过经费的引导和评估系统的改革, 引导科研人员投人更 多地关注基因编辑技术本身. 因为没有一个技术是终极技 术, 基因编辑技术肯定也会有更新换代, 肯定是要不断完 善的. 我希望我们能在这方面做更多的工作. 另外, 我觉得 我们没有必要近期在存在很大的伦理风险和安全性挑战的 领域投人太多的精力. 除了发展技术本身之外，我们应该 更多的考虑，在技术还没有完全成熟的情况下，如何利用 基因编辑技术来发展基础研究, 比如在实验动物水平, 在 早期胚胎发育的研究方面可以做更多的研究工作. 另外一 个潜在的应用在于, 我们可以利用基因编辑技术创造有价 值的动物模型. 利用基因编辑的手段, 改变一些动物的生 理特性, 改善生产性状, 建立人类疾病的动物模型. 在所有 这些从技术、科学、到动物水平上的疾病研究前期工作有一 定的基础之后, 我们再来考虑将基因编辑技术应用于人类上 做更多贡献. 科学研究肯定是要一步步渐进的, 但当务之急 我觉得还是在关键的核心技术发掘上. 我们如何能够在基因 编辑核心技术的发展上, 做出一些创造性的, 有自己的专利 和产权的工作, 这也是从我的角度最期待的”.

赵欣 中国科学院微生物研究所, 北京 100101 赵迎泽

中国疾病预防控制中心，病毒病预防控制所，北京 102206

\section{推葆阅读文献}

1 Liang P, Xu Y, Zhang X, et al. CRISPR/Cas9-mediated gene editing in human tripronuclear zygotes. Protein Cell, 2015, 6: 363-372 